\title{
Orthorexia and anorexia nervosa: two distinct phenomena? A cross-cultural comparison of orthorexic behaviours in clinical and non-clinical samples
}

\author{
C. Gramaglia" ${ }^{1 *}$ A. Brytek-Matera², R. Rogoza ${ }^{3}$ and P. Zeppegno ${ }^{1}$
}

\begin{abstract}
Background: Orthorexia nervosa (ON) is defined as pathological healthful eating. The aim of this study was to investigate whether there is any difference in orthorexic behaviours between clinical and non-clinical groups, and in different cultural contexts.

Methods: Recruitment involved both female patients with anorexia nervosa (AN) and healthy controls (HC) from Italy and Poland ( $N=23$ and $N=35$ AN patients; and $N=39$ and $N=39 \mathrm{HCS}$, in Italy and Poland, respectively). Assessment of orthorexic behaviours was performed with the ORTO-15 test.

Results: Statistically significant differences were found between Italian women in the AN and HC group, whereas no difference between Polish women in the AN and HC group was found. Both Italian groups scored significantly higher than the Polish ones on the ORTO-15.

Conclusions: Differences have been found between the Italian and Polish samples, both in the percentage of individuals with orthorexic behaviours as suggested by an ORTO 15 score below the cutoff, and in the mean ORTO 15 scores in the AN and HC groups, suggesting cross-cultural differences in orthorexic behaviours, whose meaning is currently difficult to understand.
\end{abstract}

Keywords: Anorexia nervosa, Orthorexia, Culture, ORTO-15

\section{Background}

Orthorexia nervosa $(\mathrm{ON})$ is defined as an exaggerated, obsessive, pathological fixation on healthy food, eating healthy, or rather health-conscious eating behaviours [1$3]$. The literature is not unequivocal about whether $\mathrm{ON}$ is an eating disorder (at all), a variant of a currently recognized eating disorder (ED), such as the avoidant/restrictive food intake disorder, or a different disorder [4-6]. Similarities and possible overlaps have been suggested with the spectrum of obsessive-compulsive, eating, or somatoform disorders $[5,7,8]$. Orthorexia shares issues with disturbed eating/nutrition attitudes as shown by excessive focus on

\footnotetext{
* Correspondence: carla.gramaglia@gmail.com;

carla.gramaglia@med.uniupo.it

${ }^{1}$ Psychiatry Institute, Dipartimento di Medicina Traslazionale, Università del

Piemonte Orientale, Via Solaroli n 17, 28100 Novara, Italy

Full list of author information is available at the end of the article
}

food-related topics $[9,10]$, strict diet [11], perfectionism [12], co-occurrence of anxiety, need of control [13], stiffness of behaviour and rituals related to preparation of meals $[14,15]$. In individuals with $\mathrm{ON}$, the most characteristic features of anorexia nervosa (AN) and bulimia nervosa (BN) are absent, namely excessive preoccupation with losing weight, extreme fear of gaining weight and body size overestimation [12, 16]. Reports from the literature are far from being consistent, nonetheless a high frequency of occurrence of orthorexic behaviours in patients with EDs has been described, and eating related disturbances may play the role of risk factors for orthorexia, although the reverse is also possible [17-23]. Overall, despite increasing research efforts, there is still a dearth of empirical data regarding the relation between AN and orthorexia. 
Reports are not unequivocal also as far as the correlation between eating pathology (as measured for instance with the Eating Attitudes Test) and orthorexia (as measured with the ORTO-15 test) is concerned [17, 24-28]. Moreover, while orthorexia entails both a fixation, i.e. a mental process, and specific behaviours, the ORTO-15 test, especially when using a score of 40 as threshold value, likely measures the latter (healthy eating behaviours) rather than the first (fixations and obsessive traits) [3, 29].

The aim of the present research was to assess the possible overlap between orthorexia, measured with the ORTO-15 test, and AN. For this purpose, we assessed a sample of female patients under treatment for a diagnosis of $\mathrm{AN}$, and a sample of female healthy controls (HCs) from the general population. The second aim was to assess the possible cross-cultural differences in orthorexic behaviours between Italian and Polish women, both with and without a diagnosis of AN. For this purpose, the same research procedure was carried on in two culturally different countries - Italy and Poland.

\section{Methods}

Patients with a diagnosis of AN according to DSM-5 criteria [30] were recruited both in Italy (Psychiatry Institute, Università del Piemonte Orientale, AOU Maggiore della Carità, Novara), and in Poland (the Polish National Center for Eating Disorders, Wroclaw) ( $N=23$ and $N=35$, respectively), as well as HCs from the general population $(N=39$, both in Italy and Poland). All groups included individuals aged $>18$ years, who voluntarily took part in the study after informed consent was obtained. The need for approval from the local ethics committee was waived since the study did not entail anything beyond standard and everyday clinical practice.

The ORTO-15 test [3, 29] was used as a measure of orthorexic behaviours. The ORTO-15 is composed of 15 items with closed multiple-choice answers ("always", "often", "sometimes", "never"). Items investigate the obsessive attitude of the individuals in choosing, buying, preparing and consuming food they consider to be healthy. A score equal to 1 for each item corresponds to an orthorexic tendency in the eating behaviour, while a score equal to 4 points indicates normal eating habits. Higher scores suggest normal eating habits; a cutoff of 40 or 35 points has been suggested. We used the 40-points cutoff, which according to Donini and coworkers [29] allows the identification of symptoms consistent with orthorexia nervosa with a sensitivity of $100.0 \%$, a specificity value of $73.6 \%$, a positive predictive value of $17.6 \%$ and a negative predictive value of $100 \%$. In our study we used both the
Italian and Polish [31] validated versions of the questionnaire.

Statistical analyses were performed using Chi-square test and parametric $t$ tests for independent sample to test the study hypotheses; statistical significance level was set at $\mathrm{p}$-value $<0.05$. All analyses were performed with SPSS v.22 [32].

\section{Results}

Mean age and BMI of AN and HCs from both countries are reported in Table 1, as well as the percentage of individuals scoring under the ORTO-15 cutoff (i.e. with orthorexic tendencies). No difference was found with the Chi-square test in the percentage of subjects scoring under the ORTO-15 cutoff when comparing Italian AN and Italian $\mathrm{HC}(p=.263)$, or when comparing Polish AN and Polish HC $(p=.670)$. On the contrary, the percentage of individuals with orthorexic behaviours as described by an ORTO-15 score below the cutoff was different between Italian AN and Polish AN $(p=.031)$ and between Italian and Polish HC ( $p$ $=.001)$. Descriptive statistics and normality distribution test of ORTO-15 scores in the AN and HC groups are presented in Table 2. Data in all studied samples as divided by country were normally distributed, except for the Italian AN group, likely due to the small number of patients included. Nonetheless, since both kurtosis and skewness in all samples did not exceed 1, parametric statistics were used for the analyses.

The results of the $t$-tests are presented in Table 3 . First, groups recruited in the same nation were compared. The statistical difference between Italian AN and $\mathrm{HC}$ groups was found at the boundary of the accepted threshold, whereas no differences between Polish women in the AN and HC group was found. Second, women in the $\mathrm{AN}$ and $\mathrm{HC}$ groups were compared, independently. The Italian groups scored significantly higher than the Polish ones, both for $\mathrm{AN}$ and $\mathrm{HC}$ group.

\section{Discussion}

Italian patients were older than Polish ones; regrettably data about illness duration were not available, although it is likely that the Italian AN group included patients

Table 1 Mean age, mean BMI, and \% of individuals scoring under the ORTO-15 40-points cutoff

\begin{tabular}{llll}
\hline Sample & $\begin{array}{l}\text { Mean age } \\
\text { (years) }\end{array}$ & $\begin{array}{l}\text { Mean BMl } \\
\left(\mathrm{Kg} / \mathrm{m}^{2}\right)\end{array}$ & $\begin{array}{l}\text { \% scoring under the } \\
\text { ORTO-15 40-points cutoff }\end{array}$ \\
\hline Italian AN & 30.39 & 16.36 & $60.9 \%$ \\
Italian HC & 34.41 & 22.69 & $46 \%$ \\
Polish AN & 22.97 & 17.21 & $85.6 \%$ \\
Polish HC & 23.00 & 21.69 & $82 \%$ \\
\hline
\end{tabular}


Table 2 Descriptive statistics and normality distribution test of ORTO-15 scores in the AN and HC groups (bold is for statistically significant results)

\begin{tabular}{lccccccc}
\hline Sample & $N$ & $M$ & $S D$ & Kurtosis & Skewness & $\begin{array}{c}\text { Kolmogorov-Smirnov } \\
\text { normality test }\end{array}$ & $p$ \\
\hline Italian AN & 23 & 37.21 & 1.15 & -0.97 & -0.07 & 0.20 & $\mathbf{. 0 2 4}$ \\
Italian HC & 39 & 39.41 & 0.50 & 0.61 & 0.31 & 0.12 & .191 \\
Polish AN & 35 & 34.37 & 0.83 & -0.88 & -0.20 & 0.13 & .166 \\
Polish HC & 39 & 35.36 & 0.58 & -0.74 & -0.21 & 0.10 & .200 \\
\hline
\end{tabular}

with a more severe and enduring ED, as suggested also by the lower BMI values.

In the current Italian $\mathrm{HC}$ sample, $54 \%$ scored 40 or above at the ORTO-15, suggesting the presence of orthorexic behaviours in $46 \%$ of the sample, consistent with a previous study performed in Italy and reporting a prevalence of orthorexia nervosa of 57.6\% (40-point threshold, ORTO-15), or 21\% (35-point threshold, ORTO-15) [19].

Surprisingly, in the Polish HC sample the percentage of those scoring 40 or above (i.e. those with no orthorexic tendencies) was only $18 \%$, with $82 \%$ of the sample self-reporting orthorexic behaviours as described by the ORTO-15 test. Mean scores under the 40-points cutoff [33], and percentages up to $68.55 \%$ of orthorexic behaviours measured with the ORTO-15 [34] have been described in Poland.

Differences in the mean score at the ORTO-15 were found between AN and $\mathrm{HC}$ groups in Italy, but not in Poland. Whether there is an overlap or not between AN and orthorexic behaviours, and whether this is also mediated by cultural factors should be further assessed by studies involving larger samples.

The Chi-square differences in the percentage of orthorexic behaviours suggested by an ORTO- 15 score below the cutoff, and the finding of higher ORTO-15 mean scores in Italian women than in Polish ones, independent of belonging to either the AN or the $\mathrm{HC}$ group, suggest cross-cultural differences in orthorexic attitudes and behaviours. Their meaning is currently difficult to understand, considering the lack of data about this issue. These differences are likely due to culture-related discrepancies

Table 3 Comparison of the mean ORTO-15 score in AN and $\mathrm{HC}$ groups divided by country (bold is for statistically significant results)

\begin{tabular}{llll}
\hline Group 1 & Group 2 & $t_{(\mathrm{df})}$ & $p$ \\
\hline Italian AN & Italian HC & $-2.00_{(60)}$ & $\mathbf{. 0 4 9}$ \\
Polish AN & Polish HC & $-0.98_{(72)}$ & .325 \\
Polish AN & Italian AN & $-2.06_{(56)}$ & $\mathbf{. 0 4 4}$ \\
Polish HC & Italian HC & $5.31_{(76)}$ & $\mathbf{. 0 0 1}$ \\
\hline
\end{tabular}

in the approach to food and health concept. Italy has a widely-acknowledged culture about eating and nutrition, and the Mediterranean diet has long been praised for its benefits for overall health [35, 36], but has a strong focus on taste as well. In Poland, in the last ten years, good consumer practices have gained a slightly greater popularity (e.g. checking the composition of foodstuffs). For Poles, healthy eating is the most important among various activities aimed at improving their own state of health; eight out of ten adults report eating healthy, and most Poles assess their diet as balanced [37]. This may explain the high percentage of people scoring under the ORTO-15 cutoff, i.e. selfreporting orthorexic behaviours.

Further studies are warranted to assess whether healthism or Alternative Food Networks (AFN) play a role in the differences between Italian and Poles. Healthism is a concept proposed to discuss and contextualize orthorexia, which would be an advocate for healthy eating to pursue a better health [38]. Orthorexic tendencies have been described in people actively engaged in AFN [39], but while most people are likely to do so for the benefits that this would bring to society, health and environment, currently it cannot be excluded that a small number of individuals may rather try to disguise disordered eating attitudes behind these socially acceptable (and even laudable) habits.

Limitations of this study are the relatively small sample size, which may hinder the generalizability of the current results, and the intrinsic flaws of the ORTO-15. As far as the former is concerned, regrettably it is a shared problem of most studies in the field of orthorexia [18]. As for the latter, recently it has been claimed that new tools are necessary for the assessment of orthorexia, in consideration of the limits of both the ORTO-15 and Bratman's Test $[8,40-42]$, which tend to overestimate its prevalence. While the ORTO-15 is still the most used instrument by the studies in this field, we cannot exclude the possibility that other assessment tools would yield different results. Moreover, the ORTO-15 alone is not a diagnostic tool, and regrettably in this study neither a measure of personality features was available [3] nor the suggested diagnostic criteria for ON $[2,43]$ were used.

Last, since this was a naturalistic study based on voluntary participation, the samples in Poland and Italy were not age matched. Therefore, we cannot exclude that some of the differences we found depend on age issues.

\section{Conclusions}

In the current sample, orthorexic behaviours did not overlap with AN in the Italian samples, and seemed to be influenced by cultural issues. Further studies are warranted to assess whether orthorexia is just a variant of individuals' 
ways of approaching eating and nutrition, or something different, and to disentangle the meaning of cultural differences in its prevalence.

\section{Abbreviations}

AFN: Alternative Food Networks; AN: Anorexia nervosa; BN: Bulimia nervosa; ED: Eating disorder; HCs/HC: Healthy controls; ON: Orthorexia nervosa

\section{Acknowledgements}

not applicable.

\section{Funding}

No funding was received for this research.

\section{Availability of data and materials}

The datasets used and analysed during the current study available from the corresponding author on reasonable request.

\section{Authors' contributions}

CG. and PZ. designed the study project. CG. and ABM. collected data and drafted the manuscript. RR. performed statistical analyses. PZ. critically revised the manuscript. All the Authors read and approved the final draft of the manuscript.

\section{Competing interests}

The authors declare that they have no competing interests.

\section{Consent for publication}

not applicable.

\section{Ethics approval and consent to participate}

The need for approval from the local ethics committee (Comitato Etico Interaziendale, Novara, Italy; SWPS University of Social Sciences and Humanities Human Research Ethics Committee, Katowice, Poland) was waived since the study did not entail anything beyond standard and everyday clinical practice; patients' informed consent was obtained.

\section{Author details}

${ }^{1}$ Psychiatry Institute, Dipartimento di Medicina Traslazionale, Università del Piemonte Orientale, Via Solaroli nº 17, 28100 Novara, Italy. ${ }^{2}$ SWPS University of Social Sciences and Humanities, Katowice Faculty of Psychology, Katowice, Poland. ${ }^{3}$ University of Cardinal Stefan Wyszyński, Warsaw, Poland.

Received: 24 November 2016 Accepted: 15 February 2017

\section{Published online: 21 February 2017}

\section{References}

1. Bratman S. Health food junkie. Yoga J. 1997:136:42-50.

2. Dunn TM, Bratman S. On orthorexia nervosa: a review of the literature and proposed diagnostic criteria. Eat Behav. 2016;21:11-7.

3. Donini LM, Marsili D, Graziani MP, Imbriale M, Cannella C. Orthorexia nervosa: a preliminary study with a proposal for diagnosis and an attempt to measure the dimension of the phenomenon. Eat Weight Disord. 2004; 9(2):151-7.

4. Brytek-Matera A. Healthy eating obsession in women with anorexia nervosa: a case control study. In: Gramaglia C, Zeppegno P, editors. New developments in anorexia nervosa research. New York: Nova; 2014. p. 39-50.

5. Dell'Osso L, Abelli M, Carpita B, Pini S, Castellini G, Carmassi C, Ricca V. Historical evolution of the concept of anorexia nervosa and relationships with orthorexia nervosa, autism and obsessive-compulsive spectrum. Neuropsychiatr Dis Treat. 2016;12:1651-60.

6. Vandereycken W. Meda hype, diagnostic fad or genuine disorder? Professionals' opinions about night eating syndrome, orthorexia, muscle dysmorphia, and emethophobia. Eat Disord. 2011:19(2):145-55.

7. Hadjistavropoulos $H$, Lawrence B. Does anxiety about health influence eating patterns and shape-related body checking among females? Personal Individ Differ. 2007:43(2):319-28.

8. Koven NS, Abry AW. The clinical basis of orthorexia nervosa: emerging perspectives. Neuropsychiatr Dis Treat. 2015;11:385-94.
9. Catalina Zamora ML, Bote Bonaechea B, García Sánchez F, Ríos RB. Ortorexia nerviosa. ¿Un nuevo trastorno de la conducta alimentaria? Actas Esp Psiquiatr. 2005;33(1):66-8.

10. Chaki B, Pal S, Bandyopadhyay A. Exploring scientific legitimacy of orthorexia nervosa: a newly emerging eating disorder. J Hum Sport Exerc. 2013;8(4):1045-53.

11. Varga M, Thege BK, Dukay-Szabó S, Túry F, van Furth EF. When eating healthy is not healthy: orthorexia nervosa and its measurement with the ORTO-15 in Hungary. BMC Psychiatry. 2014;14:59.

12. Brytek-Matera A. Orthorexia nervosa - an eating disorder, obsessivecompulsive disorder or disturbed eating habit? Arch Psychiatr Psychother. 2012;14(1):55-60.

13. Fidan T, Ertekin V, Işikay S, Kirpinar I. Prevalence of orthorexia among medical students in Erzurum. Turkey Compr Psychiatry. 2010;51(1):49-54.

14. Bartrina JA. Ortorexia o la obsesión por la dieta saludable. Arch Latinoam Nutr. 2007;57(4):313-5

15. Koven NS, Senbonmatsu N. A neuropsychological evaluation of orthorexia nervosa. Open J Psychiatry. 2013;3:214-22.

16. Barnes MA, Caltabiano ML. The interrelationship between orthorexia nervosa, perfectionism, body image and attachment style. Eat Weight Disord. 2016. doi:10.1007/s40519-016-0280-x.

17. Brytek-Matera A, Rogoza R, Gramaglia C, Zeppegno P. Predictors of orthorexic behaviours in patients with eating disorders: a preliminary study. BMC Psychiatry. 2015;15:252

18. Varga M, Dukay-Szabó $S$, Túry F, van Furth EF. Evidence and gaps in the literature on orthorexia nervosa. Eat Weight Disord. 2013;18(2):103-11.

19. Ramacciotti CE, Perrone P, Coli E, Burgalassi A, Conversano C, Massimetti G, Dell'Osso L. Orthorexia nervosa in the general population: a preliminary screening using a self-administered questionnaire (ORTO-15). Eat Weight Disord. 2011:16(2):e127-30.

20. Segura-Garcia C, Ramacciotti C, Rania M, Aloi M, Caroleo M, Bruni A, Gazzarrini D, Sinopoli F, De Fazio P. The prevalence of orthorexia nervosa among eating disorder patients after treatment. Eat Weight Disord. 2015; 20(2):161-6.

21. Mac EC. The price of perfection. Nutr Bull. 2001;26(4):275-6.

22. Cartwright MM. Eating disorder emergencies: understanding the medical complexities of the hospitalized eating disordered patient. Crit Care Nurs Clin North Am. 2004:16(4):515-30.

23. Kinzl JF, Hauer K, Traweger C, Kiefer I. Orthorexia nervosa in dieticians. Psychother Psychosom. 2006;75(6):395-6.

24. Sanlier N, Yassibas E, Bilici S, Sahin G, Celik B. Does the rise in eating disorders lead to increasing risk of orthorexia nervosa? correlations with gender, education, and body mass index. Ecol Food Nutr. 2016;55(3):266-78.

25. Asil E, Sürücüoğlu MS. Orthorexia nervosa in Turkish dietitians. Ecol Food Nutr. 2015;54(4):303-13.

26. McInerney-Ernst EM. Orthorexia nervosa: real construct or newest social trend? University of Missouri-Kansas City. 2011. https://mospace.umsystem. edu/xmlui/handle/10355/11200

27. Segura-García C, Papaianni MC, Caglioti F, Procopio L, Nisticò CG, Bombardiere L, Ammendolia A, Rizza P, De Fazio P, Capranica L. Orthorexia nervosa: a frequent eating disordered behavior in athletes. Eat Weight Disord. 2012:17(4):e226-33.

28. Bundros J, Clifford D, Silliman K, Neyman MM. Prevalence of orthorexia nervosa among college students based on Bratman's test and associated tendencies. Appetite. 2016;101:86-94.

29. Donini LM, Marsili D, Graziani MP, Imbriale M, Cannella C. Orthorexia nervosa: validation of a diagnosis questionnaire. Eat Weight Disord. 2005;10:e28-32.

30. American Psychiatric Association. Diagnostic and statistical manual of mental disorders. 5th ed. Arlington: American Psychiatric Publishing; 2013.

31. Brytek-Matera A, Krupa M, Poggiogalle E, Donini LM. Adaptation of the ORTHO-15 test to polish women and men. Eat Weight Disord. 2014;19(1):69-76.

32. Corporation IBM. IBM SPSS statistics for windows, version 22.0. Armonk: IBM Corporation; 2013

33. Hyrnik J, Janas-Kozik M, Stochel M, Jelonek I, Siwiec A, Rybakowski JK. The assessment of orthorexia nervosa among 1899 polish adolescents using the ORTO-15 questionnaire. Int J Psychiatry Clin Pract. 2016;20(3):199-203.

34. Brytek-Matera A, Donini LM, Krupa M, Poggiogalle E, Hay P. Orthorexia nervosa and self-attitudinal aspects of body image in female and male university students. J Eat Disord. 2015;3:2. 
35. Sofi F, Abbate R, Gensini GF, Casini A. Accruing evidence on benefits of adherence to the Mediterranean diet on health: an updated systematic review and meta-analysis. Am J Clin Nutr. 2010;92(5):1189-96.

36. Schwingshackl L, Missbach B, König J. Hoffmann G adherence to a Mediterranean diet and risk of diabetes: a systematic review and metaanalysis. Public Health Nutr. 2015;18(7):1292-9.

37. CBOS (Centrum Badania Opinii Społecznej). Zachowania żywieniowe Polaków. Nr 115/2014. Warszawa. 2014. http://www.cbos.pl/SPISKOM.POL/ 2014/K_115_14.PDF. [Public Opinion Research Center. Poles' feeding behaviours. No 115/2014. Warsaw]

38. Håman L, Barker-Ruchti N, Patriksson G, Lindgren EC. Orthorexia nervosa: an integrative literature review of a lifestyle syndrome. Int I Qual Stud Health Well-being. 2015;10:26799.

39. Barnett MJ, Dripps WR, Blomquist KK. Organivore or organorexic? examining the relationship between alternative food network engagement, disordered eating, and special diets. Appetite. 2016;105:713-20.

40. Missbach B, Dunn TM, König JS. We need new tools to assess orthorexia nervosa. A commentary on "prevalence of orthorexia nervosa among college students based on Bratman's test and associated tendencies.". Appetite. 2016. doi:10.1016/j.appet.2016.07.010.

41. Dunn TM, Gibbs J, Whitney N, Starosta A. Prevalence of orthorexia nervosa is less than 1\%: data from a US sample. Eat Weight Disord. 2016. doi:10. 1007/s40519-016-0258-8.

42. Missbach B, Hinterbuchinger B, Dreiseitl V, Zellhofer S, Kurz C, König J. When eating right, is measured wrong! a validation and critical examination of the ORTO-15 questionnaire in German. PLoS One. 2015;10(8):e0135772.

43. Moroze RM, Dunn TM, Craig Holland J, Yager J, Weintraub P. Microthinking about micronutrients: a case of transition from obsessions about healthy eating to near-fatal "orthorexia nervosa" and proposed diagnostic criteria. Psychosomatics. 2015;56(4):397-403.

\section{Submit your next manuscript to BioMed Central and we will help you at every step:}

- We accept pre-submission inquiries

- Our selector tool helps you to find the most relevant journal

- We provide round the clock customer support

- Convenient online submission

- Thorough peer review

- Inclusion in PubMed and all major indexing services

- Maximum visibility for your research

Submit your manuscript at www.biomedcentral.com/submit

C) Biomed Central 